\title{
Attitudes towards Fake News: A Systematic Literature Review
}

\author{
Shaikha Mohammed Ali Bin Helal Alkhateri \\ Institut Pengurusan Teknologidan Keusahawanan, Universiti Teknikal Malaysia Melaka, \\ Malaysia.
}

\section{S. Indra Devi}

Pasat Pembelajaran Bahasa, Universiti Teknikal Malaysia Melaka, Malaysia.

\section{Zanariah Jano}

Institut Pengurusan Teknologidan Keusahawanan, Universiti Teknikal Malaysia Melaka, Malaysia.

\section{Samer Ali Al-shami}

Faculty of Technology Management \& Technopreneurship, Universiti Teknikal Malaysia Melaka, Malaysia.

E-mail: samerali@utem.edu.my

Received February 10, 2021; Accepted June 07, 2021

ISSN: $1735-188 X$

DOI: 10.14704/WEB/V18SI03/WEB18099

\section{Abstract}

The rise of social media has provided a means for the spread of fake news, factual false information that is used to further a financial, political or societal agenda. The response to fake news on social media can be from individual users, social media platform companies, or respective national governments. This systematic literature review was designed to determine whether there is commonality across cultures and nations as to fake news exposure, response to encountering fake news on social media, and attitudes towards mediating efforts. A total of five published journal articles were selected, each using quantitative methods and representing five distinct geographical areas. These articles formed the bases for a systematic literature review that answered the research questions concerned with attitudes towards the threat of fake news, responses to fake news encountered on social media platforms, and attitudes towards efforts to curb fake news, whether by individuals, social media platform companies, or governments. Results showed universal recognition of fake news as a potential or real threat, mixed results as to whether fake news is read or shared by respondents, and mixed results regarding which actor (people, companies or governments) should lead mitigation efforts. These results emphasize the cultural and societal differences that must be considered when investigating fake news, particularly with the intention to develop recommendations or guidelines for its reduction. 


\section{Keywords}

Attitudes, Fake, News.

\section{Introduction}

Social media platforms have offered an unprecedented opportunity to share information and knowledge worldwide, but at the same time it has created an environment where fake news can be shared just as easily. The consequences of such activity can range from the spread of minor rumors or misinformation to sparking major incidents or national crises (Bentzen, 2017; Mirghafoori et al, 2020).

The rise in social media usage is a worldwide phenomenon, with all countries affected by the rapid spread of news - fake or real (Bali \& Desai, 2019; Lee, 2019). Given the global potential threat of fake news, this research investigates current public opinions from different countries in order to determine whether there are similarities in thought about the threat of fake news, how people interact with fake news and opinions on the best way to combat it.

Fake news is information that is presented as factual but is not. Allcott and Gentzkow (2017) define it as false news that is deliberately created and spread either through traditional media (television, newspapers, etc.) or digital/social media with the hope of political advantage or because of financial incentives. The threat of fake news is that once it is shared it can either damage reputations or convince people to hold certain opinions or even inspire them to action (Raj \&Goswami, 2020). Additionally, there can be an element of subjectivity about what fake news means, which makes it even more challenging to create an effective policy or conduct meaningful research (Bali \& Desai, 2019).

Methods of combatting fake news generally fall into three categories depending on which party is at focus: the individual social media user, governments, or the social media platforms (Reuter et al, 2019).

\section{Methods}

This research comprises a systematic literature review of published research papers on the topic of fake news. Cooper (1988) defines a systematic literature review as using primary research reports, and then inductively describing or summarizing these reports. In order to determine whether there are similar opinions about fake news among people in a global context, a systematic literature review allows the collection of data and information from published research conducted in different countries. 
The approach taken by Avella et al (2016), as informed by Cooper (1988), was followed for the creation of a methodology. This approach involved following a systematic procedure to identify and analyze the chosen reports in order to collect relevant data.

\section{Formulating the Problem}

Fake news has been clearly established as a phenomenon of concern, However, the level of perceived risk may vary by country. Additionally, the response of the public to fake news may differ, including the measures people feel would be most effective or appropriate to combat the spread of fake news. Therefore the following research questions are indicated:

RQ1 Do people consider fake news a threat?

RQ2 Do people read or share fake news?

RQ3 What do people think is the best method to combat fake news?

\section{Data Collection}

In order to obtain the right data, a search was conducted on an online journal database to include published, peer-reviewed articles of original research. These articles had been published within the past two years (2019-2020). Additionally, the location of the research was deliberately noted in order to make sure that the articles chosen represented a range of different geographical areas. Preference was given to quantitative research, and the research questions of the articles must align or otherwise inform the topics or questions under study in this research. Several articles were more comprehensive, meaning they discussed a broader range of topics. However, as long as the research included topics that were relevant to the themes of this research they were considered.

\section{Data Evaluation}

Five published research papers were selected for review, listed in Table 1. Each represented a different country that was geographically distant from the others in order to have a wider range of representation. The research questions did not always exactly match each question under consideration here, Nevertheless all the appropriate data and conclusions were included. 
Table 1 Selected articles for the Systematic Literature Review

\begin{tabular}{|l|l|l|l|}
\hline Author(s) & Title & Year & Country \\
\hline $\begin{array}{l}\text { Reuter, Hartwig, } \\
\text { Kirchner, Schlegel }\end{array}$ & $\begin{array}{l}\text { Fake News Perception in Germany: A } \\
\text { Representative Study of People's Attitudes } \\
\text { ad Approaches to Counteract } \\
\text { Disinformation }\end{array}$ & 2019 & Germany \\
\hline Raj, Goswami & $\begin{array}{l}\text { Is Fake news Spreading More Rapidly than } \\
\text { COVID-19 in India? }\end{array}$ & 2020 & India \\
\hline $\begin{array}{l}\text { Rampersad, } \\
\text { Althiyabi }\end{array}$ & $\begin{array}{l}\text { Fake news: Acceptance by demographics } \\
\text { and culture on social media }\end{array}$ & 2020 & Saudi Arabia \\
\hline $\begin{array}{l}\text { Wasserman, } \\
\text { Madrid-Morales }\end{array}$ & $\begin{array}{l}\text { Fake News', Disinformation and Media } \\
\text { Trust in Africa: A Comparative Study of } \\
\text { Kenya, Nigeria and South Africa }\end{array}$ & 2019 & $\begin{array}{l}\text { Kenya, Nigeria, } \\
\text { South Africa }\end{array}$ \\
\hline Yang, Horning & $\begin{array}{l}\text { Reluctant to Share: How Third Person } \\
\text { Perceptions of Fake News Discourage } \\
\text { News Readers from Sharing "Real News" } \\
\text { on Social Media }\end{array}$ & 2020 & United States \\
\hline
\end{tabular}

\section{Results}

Each article was reviewed and analyzed, with the data collected in a table in order to facilitate comparison and to draw conclusions (see Table 2).

\section{Table 2 Data from Systematic Literature Review}

\begin{tabular}{|l|l|l|l|}
\hline Country & sample & size & Conclusions \\
\hline Germany & $\begin{array}{l}\text { adult citizens, 18- } \\
\text { 64, range of } \\
\text { education and } \\
\text { income }\end{array}$ & 1023 & $\begin{array}{l}\text { Majority perceived fake news as a threat (84\%) } \\
\text { Those seeing it as a threat approved of all measures } \\
\text { to combat it. } \\
\text { Nearly half (48\%) feel the government should take } \\
\text { steps to curb fake news. } \\
\text { Only 7\% said they have shared fake news. }\end{array}$ \\
\hline $\begin{array}{l}\text { India } \\
\text { Saudi } \\
\text { Arabia }\end{array}$ & $\begin{array}{l}\text { adult university } \\
\text { students }\end{array}$ & 107 & $\begin{array}{l}\text { Majority stated fake news creates unnecessary panic. } \\
\text { Majority have spread fake news. } \\
\text { Most agree with the government taking steps to curb } \\
\text { fake news (older group more than younger). }\end{array}$ \\
\hline $\begin{array}{l}\text { Kenya, } \\
\text { Nigeria, } \\
\text { South } \\
\text { Africa }\end{array}$ & adults & $\begin{array}{l}\text { Age and education have an important influence on } \\
\text { the acceptance of fake news. } \\
\text { Culture plays a pivotal role on the spread of fake } \\
\text { news. }\end{array}$ \\
\hline $\begin{array}{l}\text { United } \\
\text { States }\end{array}$ & adults & $\begin{array}{l}\text { Vast majority come across fake news } \\
\text { sometimes/often. } \\
\text { Comparing responsibility among individuals, social } \\
\text { media providers and governments, greater emphasis } \\
\text { placed on individuals over the others. } \\
\text { Consistent exposure to fake news erodes trust in } \\
\text { media. }\end{array}$ \\
\hline
\end{tabular}




\section{Germany}

In Germany, Reuter et al (2019) wanted to get a general opinion of citizens' attitudes towards fake news, not in response to a specific event. An online survey was conducted on 1023 adults, the vast majority of whom (92\%) used a smartphone at least daily. A nearly equal majority saw fake news as a potential threat, and specifically as a threat to the government/society. In questions about accountability and the prevention of the spread of fake news, $82 \%$ felt that social media platform operators are responsible and $70 \%$ see that as a duty of the government. Regarding the reading and/or sharing of fake news, about half of the participants stated they had seen fake news online, and a very minimal $11 \%$ admitted they had either started or shared fake news.

\section{India}

India has grappled with the most extreme effects of the spread of fake news, which in several instances has led to violence. In these cases fake news has been shared to the extent that public opinion is swayed, anger is riled have resulting in violence is the result. There were 32 deaths attributed to the spread of false rumors on social media in 2018 in India. Therefore, the issue on the awareness and spread of fake news takes on a more immediate concern (Bali \& Desai, 2019).

Raj and Goswami (2020) conducted a survey of 300 people, under 20 for over 34 years, during the nationwide lockdown in response to the Coronavirus (Covid-19). Their primary interest was to see whether demographic variables impacted participants' interaction with social media and fake news, and how they felt about steps that could be taken to limit the spread of fake news. The vast majority of participants viewed fake news as a threat that creates unnecessary panic. However, most felt it was impossible to difficilitated fake news from real news, and did not think it should be illegal to share fake news. The majority admitted to sharing fake news. When considering potential measures to reduce the spread of fake news, most did not approve of a formal government agency but did approve of harsh measures against those who spread fake news, even though they themselves did not self-regulate or check the truthfulness of the news they forwarded. Raj and Goswami (2020) pointed to the possible impact of social identity and gratification theories, where people are sharing fake news as a way to maintain their acceptance in social and achieve a sense of gratification. 


\section{Saudi Arabia}

Rempersad and Althiyabi (2019) investigated the attitudes towards the acceptance of fake news among university students from Saudi Arabia. They were interested to see how demographics might impact attitudes towards fake news, but also importantly culture and whether cultural traits in Saudi Arabia (such as collectivism and avoiding uncertainty) might also play a role. They had 107 participants who were Saudi university students studying abroad. Their results showed that of the three demographic factors targeted (age, gender and education), age had the greatest impact. Culture had a stronger effect, also reflected in a study by Martin and Hassan (2019) where they found that among five Arab countries (Saudi Arabia, Lebanon, Qatar, Tunisia and the United Arab Emirates), Saudi citizens were more likely to report exposure to fake news as the government has enacted stricter regulations and penalties for spreading false rumors. Both studies highlight the importance of country-specific research.

\section{Kenya, Nigeria and South Africa}

In a study of three sub-Saharan African countries, Wasserman and Madrid-Morales (2019) wanted to see how prevalent fake news is in those areas and whether there was an erosion of trust in the media because of fake news. They used an online survey with 755 participants, and found that nearly all had at least some exposure to fake news, in numbers greater than a comparative study that had been conducted in the United States by the Pew Research Center in 2017. Approximately a third reported that they had shared fake news online unknowingly, while nearly a quarter had done so deliberately. When looking at who should be responsible for stopping the spread of fake news, the highest scores were for individual responsibility for fact checking, with social media platforms less so and government regulation the least favored.

\section{United States}

Fake news has become an increasing problem in the United States, with headlines focusing on the use of social media and fake news not only for advertising and market share concerns, but also to influence elections and larger-scale public perceptions (Allcott \& Gentzkow, 2017). Yang and Horning (2020) wanted to see whether there was a difference in how people saw fake news influencing themselves versus other people (third person perception) and how they feel about measures taken to limit the spread of fake news. They conducted an online survey of 335 adults whose major source of news was online media. 
Respondents reported serious concern about the threat of fake news, but saw others as more likely to be fooled by fake news than them. They did not support government intervention or regulatory measures to curb the spread of fake news. The researchers did not specify social media platform initiatives to limit fake news in their survey. However, they opened the possible compatibility with participant dislike of government regulation by discussing the algorithms and gatekeeping already in place by these companies which could be tuned to filter out fake news. Interestingly, their results showed that on the issue of individual responsibility towards combating fake news, respondents were more likely to self-censor or be more cautious about sharing news if they feel fake news is having an impact on others.

\section{Discussion}

This systematic literature review sought to determine public attitudes towards fake news and the act of limiting them is similar across countries. The review included published research from five geographically distant countries/areas (Germany, India, Saudi Arabia, sub-Saharan Africa, the United States) which both answered the research questions and offered interesting notes for further consideration.

\section{Do People Consider Fake News a Threat?}

Across all five articles, participants uniformly viewed fake news as a threat to greater or lesser degrees. Some viewed it as a potential threat to government order (Germany), others had a more direct exposure to fake news used as a means to impact government and society (United States), while others had experienced violent results from the spread of false rumors (India). All recognized at least the potential for fake news to have a negative impact on their societies, if not having experienced it directly already.

\section{Do People Read or Share Fake News?}

Results regarding exposure to fake news was more mixed. All reported at least some experience with fake news, with participants in India and Kenya, Nigeria and South Africa reporting greater levels of exposure and also higher percentages of those who have shared fake news, accidentally or even deliberately. There was discussion here about the potential cultural differences, where societal pressures may impact the need to share fake news along with a sense of personal gratification. 


\section{What Do People Think is the Best Method to Combat Fake News?}

Perhaps the area with the most differences between countries is the issue of how fake news is best countered. Nearly all saw the need for self-censoring, each individual being more aware and careful about the news that they share. The exception was Germany, which already reported a minimal $11 \%$ of participants who had shared fake news knowingly or unknowingly. There were stronger opinions about whether governments should take a strong position on setting legislation or establishing agencies to combat the spread of fake news. Germany and Saudi Arabia both viewed the role of government as pivotal, while in the other three articles participants were more reluctant to see government intervention in social media to that extent.

\section{Conclusion}

Fake news is a global phenomenon that is recognized by people as a potential or real threat to society and security. Most have seen fake news to greater or lesser degrees. However, beyond this there are clear differences. Some people are more likely to read and share fake news, whether deliberately or on purpose, which could be due to cultural differences or other factors. Additionally, there is a difference of opinion about the best methods to curb fake news, with some seeing the government as being capable and as an important caretaker while others having a more cautious view. The takeaway from that complexity is that the issue of fake news, while important in every context, must be evaluated and addressed in each individual circumstance in order the balance the needs and wants of the citizenry with the maintenance of law and order.

\section{References}

Allcott, H., \& Gentzkow, M. (2017). Social media and fake news in the 2016 election. Journal of economic perspectives, 31(2), 211-36.

Avella, J.T., Kebritchi, M., Nunn, S.G., \& Kanai, T. (2016). Learning analytics methods, benefits, and challenges in higher education: A systematic literature review. Online Learning, 20(2), 13-29.

Bali, A., \& Desai, P. (2019). Fake News and Social Media: Indian Perspective. Media Watch, 10(3), 737-750.

Bentzen, N. (2017). Understanding disinformation and fake news. European Parliamentary Research Service.

Cooper, H.M. (1988). Organizing knowledge syntheses: A taxonomy of literature reviews. Knowledge in society, 1(1), 104-126.

Lee, T. (2019). The global rise of "fake news" and the threat to democratic elections in the USA. Public Administration and Policy. 
Martin, J.D., \& Hassan, F. (2020). News Media Credibility Ratings and Perceptions of Online Fake News Exposure in Five Countries. Journalism Studies, 1-19.

Mirghafoori, S.H., Sayyadi Toranlu, H., \& Dehghani Ashkezari, J. (2020). Provision of a Model to Spread the Use of Information Technology in Serving. SRPH Journal of Interdisciplinary Studies, 2(1), 1-6.

Raj, A., \& Goswami, M.P. (2020). Is fake news spreading more rapidly than COVID-19 in India. Journal of Content, Community and Communication, 11(10), 208-220.

Rampersad, G., \& Althiyabi, T. (2020). Fake news: Acceptance by demographics and culture on social media. Journal of Information Technology \& Politics, 17(1), 1-11.

Reuter, C., Hartwig, K., Kirchner, J., \& Schlegel, N. (2019). Fake news perception in Germany: A representative study of people's attitudes and approaches to counteract disinformation.

Wasserman, H., \& Madrid-Morales, D. (2018). Fake news, disinformation and media trust in Africa: A comparative study of Kenya, Nigeria and South Africa. In ICAfrica Biennial Conference.

Yang, F., \& Horning, M. (2020). Reluctant to Share: How Third Person Perceptions of Fake News Discourage News Readers from Sharing "Real News" on Social Media. Social Media+ Society, 6(3), 2056305120955173. 